\title{
Conference Trends: Content Analysis of Education in-Service Sessions
}

\author{
Mark Kiehn \\ Associate Professor \\ Pao Lor \\ Professor and Chair \\ Mary Gichobi \\ Assistant Professor \\ Department of Education \\ University of Wisconsin in Green Bay \\ Green Bay, Wisconsin, United States.
}

\begin{abstract}
An examination of current trends in conference programming reflects the recent changes in education that have transformed instruction and learning. The 239 sessions of the Twenty-third International Conference on Learning were categorized in this study according to categorical purpose: educational, round table, general, business meeting, and social/reception sessions. Data were classified according to 10 subject areas including administration, research, instruction, diversity, inclusion, and advocacy sessions. Data revealed both changing and several new trends. The largest proportionate subject areas were teaching instruction (36\%) and research presentation sessions (25\%); followed by instructional technology (11\%), teacher preparation (9\%), and administration sessions (8\%) within educational, general, and round table session categories. The largest proportion of sessions by focus within the subject area was pedagogy (53\%), followed by sessions involving teaching post-secondary level students, and assessment of student learning. A sizeable proportion of sessions (8\%) comprised the "other topics" content, and these new trends were STEM (Science, Technology, Engineering, and Mathematics), creative thinking, and social intelligence session themes. Inclusion and special education comprised $4 \%$ of all sessions, which is consistent with reports from the literature.
\end{abstract}

Keywords: content analysis, professional development, pedagogy, diversity

\section{Conference Trends 1 \\ Conference Trends 2 \\ Conference Trends $\mathbf{3}$}

The International Conference on Learning (ICL) is a series of conferences that began in Sydney, Australia with a focus on literacy and learning. Since its inception in 1989, the focus of the conference has broadened, though literacy and learning has remained the conference theme (Common Ground Publishing, 2016). The thematic scope of the ICL has broadened upon recognition of the multiple definitions of literacy and learning in the education literature (Cornett, 2007).

Educators from school districts and higher education institutions throughout the world participate annually in conferences that facilitate professional development. In accordance with other studies, educators appear to value sessions that refine their expertise, seeking knowledge that leads to staying on the cutting edge (Bush, 2007; Wilson and Berne, 1999), and learning new pedagogies required for renewing licensure (Shuler, 1995; Todd and Hancock, 2016). If improving the quality of conferences and tailoring the sessions to meet the needs of participants is a goal, then understanding the content of conference sessions may provide valuable insight to Educators, administrators, conference organizers, and policy makers. The literature contains very few studies on state level in-service conferences, and less research on national or international conferences; with the bulk of published work in the music education field. Price and Orman (2001), Orman and Price (2007), Kiehn and Kimball (2008), and Todd and Hancock (2016) indicate the content of in-service sessions may be a reflection of the interests, focus, direction, and concerns of those affiliated with a particular professional organization. 
Researchers in other highly specialized disciplines have conducted conference content analyses to gain insights regarding their professions where information is constantly Conference Trends 4 evolving (e.g., Berryman, 1982; Conger, 1997; Fetro and Drolet, 1991; Graneheim and Lundman, 2004; Helwig and Schmidt, 2011; Jacobs and McFarlane, 2005; Kowitlawakul, 2013; Richmond, 1983).

While there is a growing body of music education literature regarding state and national level conferences (Grashel, 2007; Kantorski and Stegman, 2006; Orman and Price, 2007; Todd and Hancock, 2016), there appears to be a clear and present need for research that examines the professional development sessions for general teachers at international level conferences.

Literature Review

A review of related literature in music education reveals several studies on the analysis of conference in-service sessions; however, these findings point to several trends applicable to general education. Price and Orman (1999) conducted a content analysis of sessions at the Music Educators National Conference (MENC) National Biennial In-Service Conference from 1984 through 1998. The researchers concentrated on proportional data, given the wide fluctuation in the number of total sessions offered at each conference. The largest proportion of sessions was educational $(\mathrm{M}=60 \%)$, with performance-centered and industry-centered sessions accounting for 30\% and 18\% of total sessions offered respectively. The researchers reported multicultural music and research accounted for less than $10 \%$ of the educational sessions, and inclusion (exceptionalities) less than 5\% of the offerings. Price and Orman applied a form of inter-judge agreement in their research design, thus developing the content analysis methodology for music education research.

Price and Orman (2001) studied the 2000 MENC Biennial In-Service Conference Conference Trends 5 sessions in comparison to results previously reported in Price and Orman (1999). This research established a precedence by establishing a scholarly line of inquiry with conference content analysis research in music education. Similar to Price and Orman (1999), education (65\%) was the largest proportionate category of sessions. The authors refined the data collection form and categorization procedure to classify conference components. A form of inter-judge agreement was applied in Price and Orman's design, thus developing content analysis methodology for future music education research.

A follow-up study was conducted by Orman and Price (2007) to compare conference sessions from 2002 through 2005 in four regional level conferences connected to the MENC and two other national organizations in music. The purpose was to determine if trends reported for the MENC 1984 through 2000 conferences had continued or changed. Results confirmed educational sessions as the largest proportionate category (74\%), and industrycentered sessions continued to dominate subject areas. Further analyses revealed research accounted for less than $7 \%$; followed by technology $6 \%$, multicultural $3 \%$, and exceptionalities $0.6 \%$ of the total MENC regional conference offerings.

The Wisconsin Music Educator Association State Annual In-Service Conference sessions from 2004 through 2007 were examined by Kiehn and Kimball (2008) utilizing methods developed by Price and Orman $(1999,2001)$ and Orman and Price (2007). The largest areas of representation were educational, teacher education, and industry-centered sessions. Educational sessions represented an average of almost $66 \%$ of the total sessions $(\mathrm{N}=$ 290), and this proportion was comparable to means reported in the music education literature. Less than $8 \%$ of the total sessions centered on instructional technology, administration, and research. Kiehn and Kimball

Conference Trends 6 also reported a continuation of declining inclusion in-service sessions. Moreover; a single session on teaching special learners resulted in the inclusion category forming only $0.2 \%$ of total conference offerings over the course of three years.

Wells (2015) analyzed content from in-service sessions of the Mississippi Valley Technology Teacher Education Conference. This state conference has held in-service sessions for more than a century, with problem solving important professional issues as the primary conference objective. Wells collected conference agendas spanning 104 years, and data was coded following the eight-step protocol developed by Weber (1990). The largest proportion of sessions were teacher preparation and policy topics (54\%), with epistemology (theory of knowledge) and pedagogy topic sessions accounting for $24 \%$ and $12 \%$ respectively. The remaining proportion included a range of topics and subtopics with research comprising $6 \%$ of the total conference offerings since calendar year 1909. 
Todd and Hancock (2016) collected longitudinal data from Alabama state-level music education conference sessions to determine programming trends in comparison with the values, priorities, and interests of the affiliated organization, the National Association for Music Education. State of Alabama in-service conference sessions from 1984 to 2014 were classified by category, topic, and focus. Results demonstrated that conference sessions at the state-level reflected the national organization affiliation emphases, with the largest proportion of sessions in the educational category related to in-service teacher professional development (30\%). Within the educational category; research, multicultural, and inclusion sessions represented less than 5\% of the sessions. The purpose of this study was to examine the session contents of an international level in-Conference Trends 7 service conference in education to ascertain whether previously noted trends in the literature have stabilized, continued, or changed. Understanding the content of international conference sessions may provide valuable insight to educators, conference organizers, administrators, and policy makers. Procedures similar to those used in previous content analyses were followed to allow for a wide range of comparisons of data. This project also addresses the urgent need for more content analysis research as recommended in the literature (Kiehn and Kimball, 2008), with focus on an international level in-service conference in education.

\title{
Methodology
}

\section{Data Collection Procedure}

The entire study, including data collection, adjudicator training, and data analysis encompassed approximately 12 weeks. Data for 239 individual events were extracted from content located in the published program of the Twenty-third International Conference on Learning; a professional educator in-service conference held July 1315, 2016. Procedures used by Todd and Hancock (2016), Weber (1990), Price and Orman (1999, 2001), Orman and Price (2007) and Kippendorff (1980) were followed to allow for comparisons, and make valid inferences of trends in the present investigation. The authors of this study modified the data collection form and categorization procedure based on Kiehn and Kimball (2008) to code all conference components and organize emerging themes. The year, page number, title, sponsor (if given), and description of each session listed in the published International Conference on Learning (ICL) meeting agenda were entered into a database (Table 1). The researchers in the present study identified five conference categories, 10 subject areas, and six focus aspects within each subject area for data analysis based on Conference Trends 8 classification procedures established by Price and Orman, (1999) and Kiehn and Kimball (2008).

Table 1

Data Collection Form - Classification of Conference Components

\author{
Conference Year: \\ Page Number: \\ Title of Session: \\ Sponsor (if given): \\ Description of the session: \\ Category: \\ Subject area: \\ Focus within the subject area: \\ Other (e.g., topics of interest):
}

\section{Adjudicator Training}

Two independent judges were trained to score conference session data during a pilot study prior to the main study. To enhance reliability, the judges were trained how to categorize and classify conference session examples not included in the main study. Each judge received the data collection forms in a different random order as to not place an emphasis on one particular subject area or focus within the subject area (Amabile, 1982; Kiehn and Kimball, 2008). The two judges, both university professors, independently scored the practice session data, and independently discussed details of the scoring procedure with the author throughout two training sessions. The adjudicators were asked to consider their assessments from the training session examples as anchors. The conference program was then revealed, and the two trained judges independently classified the sessions. 


\section{Data Analysis}

Each of the 239 sessions were analyzed according to (a) categories- round table Conference Trends 9 discussions, educational sessions, general sessions, business meetings, receptions; (b) subject areas- research, instruction, technology, administration, inclusion/exceptionalities, multicultural, teacher preparation, multicultural, special education, advocacy; and (c) focus within the subject area- early childhood/elementary education, secondary education, post-secondary/adult education, assessment/evaluation, teaching pedagogy (theory, methods, and strategies), and STEM (Science, Technology, Engineering, and Mathematics) activities. One researcher independently classified all of the conference sessions. Reliability of categorization was examined by the second researcher who independently classified all sessions according to the above stated categories, subject areas, and session focus (Price and Orman, 1999; 2001). The formula [agreements/ (agreements + disagreements)] x 100 was used to determine agreement between researchers in overall session categorization. Berelson (1952) states, "in subject-matter analyses which there is high agreement on the definitions of the relevant categories, there is little difficulty in achieving validity in content analysis" (p. 169). Each researcher independently categorized the sessions, resulting in a $98.6 \%$ inter-observer agreement between judges in coded categories, subject areas, and focus within each subject area. This appears very acceptable since there were 709 possible agreements in the analysis of data, and the reliabilities reported in related literature range from 98.1 to 99.6 percent agreement between adjudicators (Kiehn and Kimball, 2008; Orman and Price, 2007; Price and Orman, 1999, 2001).

\section{Results}

Researchers in the present study analyzed all 239 sessions from the Twenty-third Conference Trends 10 International Conference on Learning. The number of sessions per day showed little fluctuation with 81 sessions on day one and day three, and a low of 77 sessions on day two of the conference. The largest proportion of sessions by category was educational (92.9\%), followed by round table discussions $(4.6 \%)$ and general sessions (2.5\%). The literature on conference session trends in education has produced dissimilar results. Data from the present study revealed both changing and several new trends. Furthermore; a variety of topics were presented at this particular conference, ranging from teachers sharing instructional pedagogy and assessment, to social intelligence and diversity presentations. The largest proportionate subject areas were instruction (36.0\%), research (25.1\%), instructional technology (10.5\%), teacher preparation (9.2\%), and administration sessions (7.5\%). A low representation of advocacy and multicultural sessions, $1.7 \%$ and $0.8 \%$ respectively, is consistent with reports from the literature (Table 2).

Table 2

Proportionate Distribution of Subject Areas within Main Categories

\begin{tabular}{lcc} 
& $n$ & \\
\hline Subject Area & $n$ & 36.0 \\
\hline Instruction & 86 & 25.1 \\
Research & 60 & 10.5 \\
Instructional Technology & 25 & 9.2 \\
Teacher Preparation & 22 & 7.5 \\
Administration & 18 & 5.0 \\
Diversity & 12 & 3.8 \\
Inclusion & 9 & 1.7 \\
Advocacy & 4 & 0.8 \\
Multicultural & 2 & 0.4 \\
Special Education & 1 &
\end{tabular}

Conference Trends 11 In contrast to the very low proportional data reported in the literature, a moderate increase surfaced in the proportion of sessions involving inclusion and special education (teaching exceptional learners in the regular classroom). Sessions on inclusion content comprised $4.2 \%$ of all sessions. A deeper analysis of data shows the distribution of focus within the subject area classifications, reported in Table 3 . The largest proportion of sessions by focus within the subject area was pedagogy $(53.1 \%)$, followed by sessions involving teaching postsecondary level students, and assessment of student learning. 


\section{Table 3 Proportionate Representation of Focus within Subject Area Classifications}

\begin{tabular}{lcc}
\hline Focus within Subject area & $n$ & $\%$ \\
\hline Pedagogy & 127 & 53.1 \\
Post-secondary level education & 36 & 15.1 \\
Assessment & 23 & 9.6 \\
Early childhood education & 20 & 8.4 \\
Secondary level education & 15 & 6.3 \\
Other topics & 18 & 7.5 \\
*STEM & $(14)$ & $(5.9) *$ \\
Creative thinking & $(2)$ & $(0.8)$ \\
Social intelligence & $(2)$ & $(0.8)$ \\
\end{tabular}

*Note: STEM is Science, Technology, Engineering, and Mathematics topics. Numerical data in parentheses is a breakdown of the "other topics" focus within the subject area.

The categorization scheme and analyses in the present study were: (a) the coding of sessions at three education levels (early childhood, secondary, post-secondary), (b) identifying sessions involving the assessment of student achievement, and (c) identifying specific session themes within the "Other topics" classification. One focus of the conference appeared to be providing experiences for teachers at different education levels. Almost one-third of all sessions Conference Trends 2 targeted post-secondary level (15.1\%), secondary level (6.3\%), and early childhood level educators $(8.4 \%)$ attending the conference. Assessment accounted for $9.6 \%$ of the total conference sessions. The "other topics" classification was analyzed to identify salient emerging themes or new trends. A sizeable proportion of sessions (7.5\%) comprised the other topics type content, and classified as STEM (Science, Technology, Engineering, and Mathematics), creative thinking, and social intelligence session themes. The data demonstrates a strong emphasis on the number of STEM learning sessions $(n=14)$, followed by an emergence of sessions on both creative thinking and social intelligence skills $(n=4)$.

\section{Discussion}

\section{Findings from the Present Study}

The purpose of this study was to examine the in-service teacher sessions of the Twenty-third International Conference on Learning (ICL) to ascertain whether previously noted content trends in the literature have stabilized, continued, or changed. Common to Price and Orman (1999, 2001), Orman and Price (2007), Kiehn and Kimball (2008), and Wells (2015); educational sessions, by far the most common, represented almost 93\% of all sessions offered at the conference. The ranging topics presented at the conference align with many current issues, initiatives, and priorities for educational research identified by professional organizations and legislation (American Educational Research Association, 2017; American Institute for Research, 2018; National Education Association, 2009; National Endowment for the Arts, 2011; United States Congress, 2015). Conference Trends 13

As previously reported in the results section of this study, the largest proportional area of representation were pedagogy, instruction, research, and instructional technology sessions. All four of these areas appear to have changed substantially in comparison to previous studies. Data demonstrate the proportion of pedagogy, instruction, research, and technology sessions have increased by 29\%, 36\%, 18\%, and 5\% respectively, in comparison to reports from the literature. Findings in the present study suggest an increased focus on administration and inclusion sessions. These data are inconsistent with the literature, where Kiehn and Kimball (2008) noted a $2 \%$ proportion compared to $7.5 \%$ in the present study for administration sessions. Recent studies in the literature report less than a $3 \%$ proportion for sessions on inclusion and special education. Inclusion and special education in the present study climbed to $4.2 \%$ of all sessions offered. In light of recent legislative emphases and institutional policy changes; teachers at all levels of instruction need proven strategies to help students with exceptionalities learn. 
Moreover; despite the small proportional increase, this trend would seem to run counter to the growing professional interest in mainstreaming and inclusion, exceptional students, and at-risk student populations (e.g., American Institute for Research, 2018; National Education Association, 2017; Shields, 2001). A national survey conducted by Gilbert and Asmus (1981) noted that $80 \%$ of the educator respondents expressed a need for some special education preparation. Perhaps more conference sessions with focus on specific topics in special education such as the student placement process, special education preparation for teachers, Individualized Education Program procedures, proven teaching methods, and practical resource materials could assist educators in working more effectively with these students. Conference Trends 14

New trends not previously noted in the literature emerged in the present study. One focus of the ICL was to provide sessions at different education levels. Almost one-third of all sessions targeted post-secondary level $(15.1 \%)$, secondary level $(6.3 \%)$, and early childhood level educators $(8.4 \%)$ attending the conference. The "other topics" classification was analyzed and the data revealed several new trends possibly connected to changes in education resulting from recent federal legislation. In contrast to the related literature, three emerging focus areas were identified within the "other topics" category: STEM (Science, Technology, Engineering, Mathematics), creative thinking, and social intelligence. There appears to be more interest in developing cognitive intelligence, higher order thinking, and executive functioning in students, as evident by a large body of literature in neuroscience (e.g., Galotti, 2011; Jensen, 2005; Sprenger, 1999) and an increase in the number of school mission statements focused on these brain-based learning aspects.

\section{Limitations of the Present Study}

Data in this study are the content of sessions from the ICL as published in the meeting agenda programs. These data are limited to session titles, brief descriptions, authors and their affiliations, and the intended participant audience. Richer data and subsequently, a deeper analysis might have been obtained by attending each conference session, had that been possible. It was assumed that the data currently available accurately represented the sessions offered at the conference.

Regarding the reliability of categorization methods in the present study; a form of inter-observer agreement was utilized to enhance consistency and accuracy, resulting in a coefficient of 98.6. This method of establishing reliability and the resulting data is comparable with reports Conference Trends 15 by Price and Orman (1999, 2001), Orman and Price (2007), and Kiehn and Kimball (2008). Analyses in the present study allowed for different emphases and numerous topics, resulting in overlapping categories. One obstacle in the present study was to design a scheme that differentiates accurately among sessions. In a similar study design, Price and Orman (1999) discuss, "while there would have been some expediency in establishing exclusive either/or categories, we felt that such dichotomous choices would neither accurately nor fairly represent the breadth of MENC's conference sessions and the variety of purposes they serve" (p. 31).

\section{Recommendations for Further Research}

Another approach to validate inferences would be to further examine data through an extended list of specific focus areas related to student learning such as educational effectiveness, equity in education, social and emotional development, human rights, school safety, school discipline, creative thinking, and critical thinking (e.g., American Institute for Research, 2018; National Endowment for the Arts, 2011). A large body of research exists for each of these focus areas, and many are grounded in foundational teaching theories. Content analysis provides an empirical basis for monitoring shifts within the context of public opinion, contemporary issues, long-range goals, and learning objectives in education. A closer examination of the research agendas in education might provide a more comprehensive view and further direction for the education profession (e.g., American Educational Research Association, 2017; Goals 2000 Arts Education Partnership, 1997; National Education Association, 2009; National Endowment for the Arts, 1994; U.S. Department of Education/Office of Educational Research and Improvement, 1996). In summary, there appears to be an immediate need for additional replication studies of Conference Trends 16 international level conferences to facilitate direct comparisons within the literature. It also would appear wise to ponder the purpose of conference sessions in reflection of the data. If the content of in-service conference sessions is intended to reflect the direction and needs of the education profession, then it seems appropriate to survey conference attendees (Friedman, 2012). The scholarly discussion regarding professional development depends heavily on more educators sharing their instructional knowledge, expertise from the field, and on-going research in future conference session presentations. Conference Trends 17 


\section{References}

Amabile, T. (1982). Social psychology of creativity: A consensual assessment technique. Journal of Personality and Social Psychology, 43 (5), 997-1013.

American Educational Research Association. (2017). Issues and initiatives in educational research. Retrieved from https://www.aera.net/Education-Research.

American Institute for Research. (2018). Priorities in educational research. Retrieved from https://www.air.org/priorities.

Berelson, B. (1952). Content analysis in communication research. Glencoe, IL: Free Press.

Berryman, C. (1982, March). Undisciplined social studies: An analysis of NCSS Programs, 1976-1980. Paper presented at the annual meeting of the American Educational Association, New York, NY.

Bush, J. (2007). Importance of various professional development opportunities and workshop topics as determined by in-service music teachers. Journal of Music Teacher Education, 16 (2), 10-18.

Common Ground Publishing. (2016, July). Conference schedule and notes. Twenty-third International Conference on Learning at the University of British Columbia, Vancouver, Canada. Champaign, IL: Author.

Conger, K. (1997, March). A content analysis study of portable assisted study sequence mathematics curricular materials for migrant students using the National Council of Mathematics Standards. Paper presented at the annual meeting of the American Educational Research Association, Chicago, IL.

Conference Trends 18

Cornett, C. (2007). Creating meaning through literature and the arts: An integration resource for classroom teachers, 2nd edition. Upper Saddle River, NJ: Pearson Publishers.

Fetro, J., \& Drolet, J. (1991). State conferences for school worksite wellness: A content analysis of conference components. Journal of Health Education, 22 (2), 80-84.

Friedman, A. (2012). Continuing professional development. New York, NY: Routledge.

Frisque, J., Niebur, L., \& Humphreys, J. T. (1994). Music mainstreaming: Practices in Arizona. Journal of Research in Music Education, 42, 94-104.

Galotti, K. M. (2011). Cognitive development. Thousand Oakes, CA: Sage Publishing.

Gfeller, K., Darrow, A., \& Hedden, S. (1990). Perceived effectiveness of mainstreaming in Iowa and Kansas schools. Journal of Research in Music Education, 38, 90-101.

Gilbert, J., \& Asmus, E. (1981). Mainstreaming: Music educators' participation and professional needs. Journal of Research in Music Education, 31, 147-155.

Goals 2000 Arts Education Partnership. (1997). Priorities for arts education research. Washington, D.C.: Author.

Graneheim, U., \& Lundman, B. (2004). Qualitative content analysis in nursing research: Concepts, procedures and measures to achieve trustworthiness. Nurse Education Today, 24 (2), 105-112.

Grashel, J. (2007). Invited study: Institutional affiliation and terminal degree university of Journal of Research in Music Education authors, editors, and editorial committee members, 1990-2005. Bulletin of the Council for Research in Music Education, 171, 7-35.

Helwig, A., \& Schmidt, L. (2011). Content analysis of 32 years of American Counseling Conference Trends

Association convention programs. Journal of Counseling and Development, 89, 148-154.

Jacobs, N., \& McFarlane, A. (2005). Conferences as learning communities: Some early lessons in using "backchannel" technologies at an academic conference- Distributed intelligence or divided attention? Journal of Computer Assisted Learning, 21 (5), 317-329.

Jensen, E. (2005). Teaching with the brain in mind, 2nd edition. Alexandria, VA: Association for Supervision and Curriculum Development Publishing.

Kantorski, V., \& Stegman, S. (2006). A content analysis of qualitative research dissertations in music education, 1998-2002. Bulletin of the Council for Research in Music Education, 168, 63-73.

Kiehn, M., \& Kimball, S. (2008). Music education conference trends: A content analysis of state in-service sessions. Journal of Education and Human Development, 2 (1), 1-10.

Kowitlawakul, Y. (2013). From novice to expert: Sharing professional development experience in different practice settings. Singapore Nursing Journal, 40 (3), 43-46.

Krippendorff, K. (1980). Content analysis: An introduction to its methodology. Beverly Hills, CA: Sage Publishing. 
National Education Association. (2009). Research issues and advocacy in higher education. Retrieved from https://www.nea.org/home/IssuesAndAction.html.

National Education Association. (2017). Special education and IDEA resources. Retrieved from https://www.nea.org/tools/special-education-IDEA-resources.html.

National Endowment for the Arts. (1994, February). Arts education research agenda for the future. Washington, D.C.: U.S. Government Printing Office, Superintendent of Documents, 94-3402.

Conference Trends 20

National Endowment for the Arts. (2011, November). The arts and human development: Framing a national research agenda for the arts, life-long learning, and individual well-being. Washington, D.C.: U. S. Department of Health and Human Services.

Orman, E., \& Price, H. (2007). Content analysis of four national music organization conferences. Journal of Research in Music Education, 55, 2. 148- 161.

Price, H. \& Orman, E. (1999). MENC national conventions 1984-1998: A content analysis. Update: Applications of Research in Music Education, 18 (1), 26-32.

Price, H. \& Orman, E. (2001). MENC 2000 national biennial in-service conference: A content analysis. Journal of Research in Music Education, 49 (3), 227-233.

Richmond, D. (1983). Improving medical meetings: I. Educate speakers and chairmen of sessions in advance. British Medical Journal, 287, 1201-1202.

Shields, C. (2001). Music education and mentoring as intervention for at-risk urban adolescents: Their selfperceptions, opinions, and attitudes. Journal of Research in Music Education, 49 (3), 273-286.

Shuler, S. (1995). The impact of national standards on the preparation, in-service professional development, and assessment of music teachers. Arts Education Policy Review, 96 (3), 2-14.

Sprenger, M. (1999). Learning and memory. Alexandria, VA: Association for Supervision and Curriculum Development Publishing.

Todd, E. D., \& Hancock, C. (2015). A 30-Year content analysis of a state-sponsored professional development conference for music educators. Bulletin of the Council for Research in Music Education, 204. 47-61.

Conference Trends 21

United States Congress. (2015). Reauthorization of the Elementary and Secondary Education Act, Public Law 107-110, Statute 1425, No Child Left Behind. Washington, D.C.: Author.

United States Department of Education/Office of Educational Research and Improvement. (1996, Dec.). Building knowledge for a nation of learners: A framework for education research 1997. Washington, D.C.: U.S. Government Printing Office, Superintendent of Documents, OAS 97-6004.

Weber, R. (1990). Basic content analysis. Beverly Hills, CA: Sage Publishing.

Wells, J. (2015). A century of professional organization influence: Findings from content analyses of MVTTEC Annual Meetings. Journal of Technology Education, 26 (3), 3-37.

Wilson, S., \& Berne, J. (1999). Teacher learning and the acquisition of professional knowledge: An examination of research on contemporary professional development. Review of Research in Education, 24, 173-209. 